\title{
DETERMINATION OF SUITABLE ELECTROLYTE FOR MAXIMUM MRR AND THE BEST SURFACE FINISH FOR MACHINING TITANIUM ALLOYS BY ECM
}

\author{
Parameswar Dash \\ Professor, Department of Mechanical Engineering, Gandhi Engineering College, Odisha, India \\ e-mail: parameswar_dash@yahoo.com
}

\begin{abstract}
:
The rapid developments in recent years of the advanced technological industries like aerospace, nuclear power etc. has been accompanied by an increasing use of "difficult-to-machine alloys" like titanium and nimonic. Some Aerospace industries manufacture $R-29 B$ engine which is fitted into MIG-27M aircraft. In this engine, six out of eleven stages of compressor rotor blades and compressor stator blades upto fifth stage are made of titanium alloys. A great deal of problems is encountered in machining these blades conventionally because of some inherent mechanical properties.These problems are multiplied due to the complexity of the blade aerofoil surface. All these problems result in frequent resharpening of tools and cams, higher machining times due to lower speed, feed \& depth of cuts, higher inventory of tools and incorporation of an intermediate belt grinding process to give required shape, size and finish to the blade. One of the methods of conveniently machining them is by electro chemical machining. (ECM).
\end{abstract}

In this paper, several experiments have been carried out to find out suitable electrolyte(s) among four electrolytes, namely Sodium Chloride ( $\mathrm{NaCl}$ ), Sodium Nitrate (NaNa3), Potassium Bromide $(\mathrm{KBr})$ \& Sodium Sulphate $\left(\mathrm{Na}_{2} \mathrm{So}_{4}\right)$ for machining titanium alloys by ECM. Experiments have been conducted by using "ANOVA"to optimize the results.

KeyWords: ANOVA, Taguchi, ECM, Electrolyte, MRR, SF etc...

\section{INTRODUCTION}

Some Aerospace industries engage themselves in the manufacturing and overhaul of aero engine for the MIG series aircraft. The R-25 engine manufactured by these industries is a jet engine and is fitted into MIG-21 BIS aircraft. These industries also produce R-29B engine which goes into MIG-27M aircraft. In this engine, some stages of compressor blades are made of titanium alloy. Titanium alloy is chosen as the blade material for compressor, primarily because of its high strength to weight ratio. But on the other hand, great difficulties are encountered, because of involvement of high cutting force and large amount of heat generated in cutting titanium alloy conventionally, the tool wear rate is very high and as such, it becomes necessary to have higher inventory of cutting tools. Also, the cycle time increases as low speeds and depth of cuts are to be employed to reduce tool wear. In order to overcome above problems associated with conventional machining, electrochemical machining makes use of a method to remove material in a controlled fashion, producing the required shape on the work piece on which the process is going on.

\section{LITERATURE SERVEY}

Following paragraphs deal in brief with the studies conducted. Professor S.K.Sorkhel \& Lect. B. Battacharyya [1] Present paper which highlights the analysis of the effect of the predominant process variables e.g., electrolyte flow rate, electrolyte concentration, current density \& applied voltage across the machining gap on the metal removal rate, surface roughness.Robert.B.Leighou [3] has explained the concept of anodic metal dissolution in an electrolytic medium \& further explains metal dissolution is an extension of the principles of Faraday's laws of electrolysis.J.A.MC. Geough [4] has discussed that Titanium is a difficult metal to machining electrochemically due to formation of tenacious oxide which prevents metal dissolution. This oxide film forms a passive layer.It is observed that the principal action in passivation is the very rapid formation of this oxide layer which becomes firmly attached to the metal and forms a barrier between it and the solution resulting low MRR.A.E.Debarr, D.A.Oliver and J.Bannard [5,6] They claimed that voltage required to breakdown the passive film could be reduced by the use of bromide \& iodide electrolytes. It was observed that the inferred hydrogen ion activity \& a consequent reaction with the solid anodic films of tenacious oxide are eventually caused a breakdown of the passive layer. R.Narayan [7] observed on the anodic dissolution of titanium alloys is the severe pitting of areas adjacent to those shaped by ECM which is completely undesirable and thereby rendering the process uncontrolled. He conducted experiments \& concluded that, over the area to be machined, there should be a large current density on the surface of the work piece but outside this area, the current density should be zero. But 
in practice, however, the current density does not abruptly drop to zero immediately outside the projected area of the tool but falls off more or less gradually, to approach zero asymptotically. Power, R.W.Wilfore J.F [8] explained the pitting of titanium alloy on areas adjacent to those shaped by ECM is related to the fact that the dissolution of these materials in an electrolyte such as $\mathrm{NaCl}$ occurs by a highly localized form of attack. The individual character of the active dissolution sites or pits is easily recognized at low current densities, whereas at larger one, the pit density is sufficiently large that the pit generally overlap and the surface appears smoothly machined. R.I.Jafee \& H.M.Burte [9] Observed a great deal of problems are encountered in machining titanium blades conventionally because of some inherent material properties. He observed, the chip-tool contact area in turning a titanium alloy is only about one third to one half as great as that for turning a steal. A.G.Degtyavenko, G.I.Fribus [10] Studied that the type of surface finish in ECM depended on the work piece material, the electrolyte used and machining condition such as electrolyte flow, current density, inter- electrode gap, concentration etc.I.I.Moroz [11] Suggests, the approximate composition of electrolytes to be used for ECM of different materials.Prof.Dr.ir.R.Snoeys(1);ir.F.Staeilens;

ir.W.Dekeyser [12] suggest the typical application of ECM Raghva Rao [13]Suggests the effectiveness of using orthogonal array design whose sole purpose is to provide the most efficient \& economical methods of reaching valid \& relevant conclusion from the experiment.Cochran.W.G,and Cox,G.M.[14] Explains the technique of analysis of variance(ANOVA) which is considered as a highly robust test. This technique enables decomposition of total variability into various component parts and indicated contribution of each of the experimental factor. Taguchi,G.and Yu Inwu [15] The author explains the technique of analysis of variance.(ANOVA).

\section{ORTHOGONAL ARRAY DESIGN:}

[14] Orthogonal Array design of experiments constitutes one type of fractional factorial design. It is a design in which all pairs of factors at particular levels appear together an equal no. of times. Orthogonal Array evolved through the concept of fractional replication (i.e. sacrificing information about interaction which are normally un-important) find itself in sound footing in minimizing the no. of factors. It is seen that when investigating the influence of fifteen factors, (each at two levels) the no. of trials can be reduced to 1/2048th of that required for a full factorial experiment by using Orthogonal Arrays (16 trials instead of 32,768).The effectiveness of using OA depends solely on the successful selection to the scheme of confounding the effects with the interaction ones, and also on the skillful strategy of running the experiment when certain interactions are significant. A priori information on the interactions does render a great service to the experimenter in this case.

\subsection{Design of Experiments}

This is the arrangement in which an experimental programme is to be conducted and the selection of the levels of one or more factors or factor combination to be included in the experiment. The purpose of designing an experiment is to provide the most efficient and economical methods of reaching valid relevant conclusion from the experiments. A properly designed experiment will permit relatively simple statistical interpretation of the result, which may not be possible otherwise. A good experimental design should have sufficient replication, adequate randomization and a good degree of local control. Replication helps to obtain internal estimation of experimental error to assess the significance of the effects sought. The influence of a factor is determined by computing the mean responses at each of its levels. In a similar way, the influence of interaction of the factors is also estimated. Further, the result is analyzed by the technique of analysis of variance (ANOVA) which is considered as a highly robust test (15). This technique enables the composition of total variability into various components parts and indicated contribution of each of the experimental factors. The significance of a factor is assessed by comparing its magnitude of variance with that of the experimental error variance by the F-test. The computed F-ratio is the ratio of the wear variance of a factor to the variance of experimental error, which is compared with the tabulated value of F-statistic at the chosen level of significance. If the computed ratio exceeds the tabulated value, the influence of the factor is considered to be significant.

\subsection{Details of Blade Used For Experimentation.}

All experiments have been carried out on fourth stage compressor rotor blade of R29B engine. The blade material has been received from the USSR with the specification VT3-1 the composition of the material is as follows:
1. Aluminium $=5.5-7.0 \%$
2. Oxygen $=0.18 \% \max$.
3. Silicon $=0.15-0.4 \%$
4. Nitrogen $=0.05 \% \max$.
5. Fircom $=0.5 \%$
6 . Hydrogen $=0.01 \%$ max.
7. Carbon $=0.1 \%$
8. Molybdenum $=2.3 \%$
9. Iron $=0.2-0.7 \%$
10. Vanadium $=0.8-2.3 \%$
11. Titanium $=$ Remaining

Moroz[11] has suggested several electrolytes for machining Titanium alloys, VT3 which is mentioned in table-1

Table -1: Suggested Electrolyte

\begin{tabular}{|l|l|}
\hline Work material & Electrolyte composition \\
\hline $\begin{array}{l}\text { Titanium alloys, } \\
\text { VT3 }\end{array}$ & $\begin{array}{l}\mathrm{NaCl}, \mathrm{KNO}_{3}, \mathrm{NaOH}, \\
\mathrm{KBr}, \mathrm{Na}_{2} \mathrm{So}_{4}, \mathrm{HCL}, \mathrm{NaNO}_{3}\end{array}$ \\
\hline
\end{tabular}

3.3 Design of experiment for finding suitable electrolyte for machining titanium alloys by ECM 
Preliminary experiments conducted for the determination of levels for ANOVA

A-Sodium chloride in $\mathrm{gm} / \mathrm{lt}$.

B-Sodium Nitrate in gm / lt.

C-Potasium Bromide in $\mathrm{gm} / \mathrm{lt}$.

D-Sodium Sulphate in gm/ lt.

In reference to Moroz (11), the suggested electrolytes for the ECM of Titanium have been given as:

A: Nacl-50gm/lt.

B: $\mathrm{NaNo}_{3}-50 \mathrm{gm} / \mathrm{lt}$.

$\mathrm{C}: \mathrm{KBr}-10 \mathrm{gm} / \mathrm{lt}$.

D: $\mathrm{Na}_{2} \mathrm{So}_{4}-5 \mathrm{gm} / \mathrm{lt}$.

Table-2: The results obtained when titanium was machined by ECM with the different combinations of electrolyte used.

\begin{tabular}{|l|l|l|l|l|l|l|}
\hline Expt. & $\mathrm{A}$ & $\mathrm{B}$ & $\mathrm{C}$ & $\mathrm{D}$ & $\mathrm{MRR}$ & $\mathrm{SF}$ \\
& & & & & $(\mathrm{g} / \mathrm{min})$ & $(\mu \mathrm{m})$ \\
\hline 1 & 60 & 60 & 20 & 20 & 1.50 & 15.30 \\
\hline 2 & 70 & 60 & 20 & 20 & 1.80 & 15.00 \\
\hline 3 & 70 & 70 & 20 & 20 & 2.00 & 14.60 \\
\hline 4 & 70 & 70 & 25 & 25 & 2.45 & 14.40 \\
\hline $\mathbf{5}$ & $\mathbf{7 5}$ & $\mathbf{7 5}$ & $\mathbf{2 5}$ & $\mathbf{2 5}$ & $\mathbf{2 . 6 0}$ & $\mathbf{1 4 . 0 0}$ \\
\hline 6 & 80 & 70 & 30 & 30 & 2.62 & 14.25 \\
\hline 7 & 80 & 80 & 30 & 30 & 2.65 & 15.50 \\
\hline 8 & 05 & 05 & 02 & 02 & 0.03 & 18.00 \\
\hline 9 & 10 & 05 & 03 & 03 & 0.08 & 13.00 \\
\hline 10 & 10 & 10 & 03 & 03 & 0.10 & 12.00 \\
\hline $\mathbf{1 1}$ & $\mathbf{1 0}$ & $\mathbf{1 0}$ & $\mathbf{0 5}$ & $\mathbf{0 5}$ & $\mathbf{0 . 1 1}$ & $\mathbf{1 1 . 5 0}$ \\
\hline 12 & 20 & 10 & 05 & 05 & 0.15 & 11.80 \\
\hline 13 & 20 & 20 & 05 & 05 & 0.18 & 12.30 \\
\hline 14 & 30 & 30 & 10 & 10 & 0.20 & 14.20 \\
\hline
\end{tabular}

From the above experiment conducted, the higher and lower levels are fixed asshown in table-3:

Table- 3: Represents the fixation of levels:

\begin{tabular}{|l|l|l|}
\hline Factors & Levels \\
\hline & Lower (1) & Higher (2) \\
\hline $\mathrm{A}-\mathrm{NaCl}$ & 10 & 75 \\
\hline $\mathrm{B}-\mathrm{NaNO}$ & 10 & 75 \\
\hline $\mathrm{C}-\mathrm{KBr}$ & 05 & 25 \\
\hline $\mathrm{D}-\mathrm{Na}_{2} \mathrm{SO}_{4}$ & 05 & 25 \\
\hline
\end{tabular}

N.B.: ECM of Titanium blade is experimented by the above mentioned electrolytes and at fixed process parameters flow rate $=4.8 \mathrm{~kg}$ per $\mathrm{cm}^{2}$, temperature of electrolyte $=$ $35^{\circ} \mathrm{C}$, gap $=0.35 \mathrm{~mm}$, voltage $=14.0 \mathrm{~V}$.

Experimental design by orthogonal array $\mathrm{L}_{8}(2)^{7}$
Table- 4:Results of MRR and SF obtained after the blade is machined by orthogonal array $L_{8}(2)^{7}$

\begin{tabular}{|l|l|l|l|l|l|l|l|l|l|}
\hline Expt. & $\mathrm{A}$ & $\mathrm{B}$ & $\mathrm{A}$ & $\mathrm{C}$ & $\mathrm{A}$ & $\mathrm{B}$ & $\mathrm{D}$ & $\mathrm{MRR}$ & $\mathrm{SF}$ \\
& & & $\mathrm{x}$ & & $\mathrm{x}$ & $\mathrm{x}$ & & & \\
& & & $\mathrm{B}$ & & $\mathrm{C}$ & $\mathrm{C}$ & & $(\mathrm{gm} / \mathrm{min})$ & $(\mu \mathrm{m})$ \\
& 1 & 2 & 3 & 4 & 5 & 6 & & & \\
\hline $15 / 16$ & 1 & 1 & 1 & 1 & 1 & 1 & 1 & $0.07 / 0.11$ & $11.1 / 12.7$ \\
\hline $17 / 18$ & 1 & 1 & 1 & 2 & 2 & 2 & 2 & $0.22 / 0.23$ & $36.6 / 34.8$ \\
\hline $19 / 20$ & 1 & 2 & 2 & 1 & 1 & 2 & 2 & $0.6 / 0.8$ & $11.1 / 9.0$ \\
\hline $21 / 22$ & 1 & 2 & 2 & 2 & 2 & 1 & 1 & $0.9 / 0.87$ & $18.2 / 19.6$ \\
\hline $23 / 24$ & 2 & 1 & 2 & 1 & 2 & 1 & 2 & $05 / 1.02$ & $21.8 / 21.5$ \\
\hline $25 / 26$ & 2 & 1 & 2 & 2 & 1 & 2 & 1 & $2.2 / 2.1$ & $12.8 / 11.4$ \\
\hline $27 / 28$ & 2 & 2 & 1 & 1 & 2 & 2 & 1 & $2.1 / 2.0$ & $15.6 / 15.1$ \\
\hline $29 / 30$ & 2 & 2 & 1 & 2 & 1 & 1 & 2 & $2.6 / 2.6$ & $13.2 / 16.8$ \\
\hline
\end{tabular}

B 2

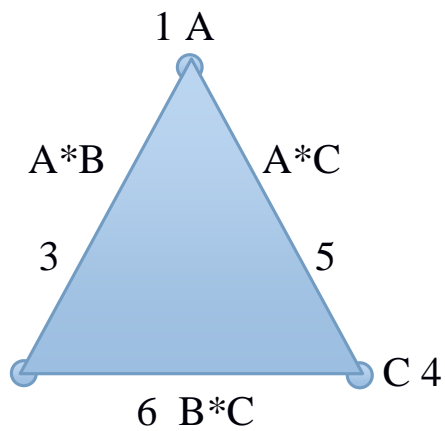

OD 7

Fig -1: Linear Graph

Degree of freedom $=1+1+1+1+1+1+1=7$

Minimum of experiments: $\mathrm{DF}+1=7+1=8$

$\mathrm{L}_{8}$ Array with 2 replications

A total of 16 experiments have been carried out.

A total degree of freedom $=16-1=15$

Table- 5: Total of MRR values at each level

\begin{tabular}{|l|l|l|l|}
\hline $\begin{array}{l}\text { Levels } \rightarrow \\
\text { factors } \downarrow\end{array}$ & I & II & Total \\
\hline A & 3.8 & 15.67 & 19.47 \\
\hline B & 7.0 & 12.47 & 19.47 \\
\hline C & 7.75 & 11.72 & 19.47 \\
\hline D & 10.35 & 9.12 & 19.47 \\
\hline A x B & 9.93 & 9.54 & 19.47 \\
\hline B x C & 9.22 & 0.25 & 19.47 \\
\hline A x C & 11.08 & 8.39 & 19.47 \\
\hline
\end{tabular}

Correction factor $\mathrm{CF}=(19.47)^{2} / 16=23.69$

Total sum of square ( with reference to table-4)

$=(0.07)^{2}+(0.11)^{2}+\ldots \ldots .+(2.6)^{2}+(2.6)^{2}-23.69=13.79$

$\mathrm{SS}_{\mathrm{A}}=\left\{(3.8)^{2}+(15.67)^{2}\right\} / 8-23.69=8.81$

In the similar manner, the values for Sum of square for other factors \& interaction of factors can be calculated and are shown in tabular form as follows :- 
Table- 6: Values of sum of square for other factors

\begin{tabular}{|l|l|}
\hline Sum of Square & Value in $\mathbf{g m} / \mathbf{m i n}$. \\
\hline $\mathrm{SS}_{\mathrm{B}}$ & 1.87 \\
\hline $\mathrm{SS}_{\mathrm{C}}$ & 0.987 \\
\hline $\mathrm{SS}_{\mathrm{D}}$ & 0.097 \\
\hline $\mathrm{SS}_{\mathrm{AxB}}$ & 0.012 \\
\hline $\mathrm{SS}_{\mathrm{BxC}}$ & 0.069 \\
\hline $\mathrm{SS}_{\mathrm{AxC}}$ & 0.455 \\
\hline
\end{tabular}

Table - 7: [Anova (for MRR)]

\begin{tabular}{|c|c|c|c|c|c|}
\hline Source & $\mathrm{df}$ & SS & $\begin{array}{l}\text { Mss } \\
=\mathrm{ss} / \mathrm{df}\end{array}$ & $\begin{array}{l}\text { Fo = } \\
\text { Mssi } \\
\text { /Mse }\end{array}$ & $\begin{array}{l}\text { Percentage } \\
\text { Contribution } \\
=\{(\text { ssi-dfi } \\
\times \text { Mse }) / T s s\} \\
* 100\end{array}$ \\
\hline $\mathrm{A}$ & 1 & 8.81 & 8.814 & 47.3 & 62.5 \\
\hline B & 1 & 1.87 & 1.87 & 10.04 & 12.2 \\
\hline $\mathrm{C}$ & 1 & 0.987 & 0.987 & 5.3 & 5.8 \\
\hline $\mathrm{D}$ & 1 & 0.097 & 0.097 & $0.52 \mathrm{~ns}$ & ---- \\
\hline$A \times B$ & 1 & 0.012 & 0.012 & $0.021 \mathrm{~ns}$ & ---- \\
\hline $\mathrm{B} \times \mathrm{C}$ & 1 & 0.069 & 0.069 & $0.37 \mathrm{~ns}$ & ---- \\
\hline $\mathrm{A} \times \mathrm{C}$ & 1 & 0.455 & 0.455 & $2.44 \mathrm{~ns}$ & ---- \\
\hline ERROR & 8 & 1.49 & 0.186 & & \\
\hline ST & 15 & 13.79 & & & \\
\hline
\end{tabular}

From $\mathrm{F}$ table for $1,8 \quad \mathrm{~F}_{1,8}=5.32$ for $99.95 \%$ confidence confidence

$$
=11.26 \text { for } 99.99 \%
$$

'ns' represents not significant

Factor "A" is highly significant.

Table- 8: Average response table for MRR

\begin{tabular}{|l|l|l|}
\hline $\begin{array}{l}\text { Levels } \rightarrow \\
\text { Factors } \downarrow\end{array}$ & I & II \\
\hline $\mathrm{A}$ & 0.475 & 1.96 \\
\hline $\mathrm{B}$ & 0.875 & 1.56 \\
\hline $\mathrm{C}$ & 0.969 & 1.47 \\
\hline $\mathrm{D}$ & 1.29 & 1.14 \\
\hline $\mathrm{A} \times \mathrm{B}$ & 1.24 & 1.19 \\
\hline $\mathrm{B} \times \mathrm{C}$ & 1.15 & 1.28 \\
\hline $\mathrm{A} \times \mathrm{C}$ & 1.39 & 1.05 \\
\hline
\end{tabular}

$\mathrm{T}=$ Average $=19.47 / 16=1.22$

Response equation for optimum MRR from table-7 \& 8 was found to be $\mathrm{A}_{\mathrm{ii}} \mathrm{B}_{\mathrm{ii}} \mathrm{C}_{\mathrm{ii}}$

Therefore, $\mathrm{MRR}=\mathrm{T}+\left(\mathrm{A}_{\mathrm{ii}}-\mathrm{T}\right)+\left(\mathrm{B}_{\mathrm{ii}}-\mathrm{T}\right)+\left(\mathrm{C}_{\mathrm{ii}}-\mathrm{T}\right)=1.22$

$+(1.96-1.22)+(1.56-1.22)+$

$(1.47-1.22)=2.55$
Table- 9: Total of surface finish values at each level

\begin{tabular}{|l|l|l|l|}
\hline $\begin{array}{l}\text { Factors/Levels } \\
\text { Interaction }\end{array}$ & I & II & TOTAL \\
\hline $\mathrm{A}$ & 153.1 & 128.2 & 281.3 \\
\hline $\mathrm{B}$ & 162.7 & 118.6 & 281.3 \\
\hline $\mathrm{C}$ & 117.9 & 163.4 & 281.3 \\
\hline $\mathrm{D}$ & 116.5 & 164.8 & 281.3 \\
\hline $\mathrm{A} \times \mathrm{B}$ & 155.9 & 125.4 & 281.3 \\
\hline $\mathrm{B} \times \mathrm{C}$ & 134.9 & 146.4 & 281.3 \\
\hline $\mathrm{A} \times \mathrm{C}$ & 98.1 & 183.2 & 281.3 \\
\hline
\end{tabular}

Table-10: Sum of Square for factors \& interaction of factors, correction factor and Total sum of square

\begin{tabular}{|l|l|}
\hline Sum of square & Value in $\boldsymbol{\mu m}$ \\
\hline $\mathrm{SS}_{\mathrm{A}}$ & 38.75 \\
\hline $\mathrm{SS}_{\mathrm{B}}$ & 121.55 \\
\hline $\mathrm{SS}_{\mathrm{C}}$ & 129.39 \\
\hline $\mathrm{SS}_{\mathrm{D}}$ & 145.80 \\
\hline $\mathrm{SS}_{\mathrm{AxB}}$ & 58.14 \\
\hline $\mathrm{SS}_{\mathrm{BxC}}$ & 8.26 \\
\hline $\mathrm{SS}$ & 452.62 \\
\hline $\mathrm{CF}$ & 4945.61 \\
\hline $\mathrm{TSS}$ & 961.49 \\
\hline
\end{tabular}

Table - 11: Anova (for surface finish)

\begin{tabular}{|l|l|l|l|l|l|}
\hline Source & df & ss & $\begin{array}{l}\text { Mss= } \\
\text { Ss/df }\end{array}$ & $\begin{array}{l}\text { Fo= } \\
\mathbf{M s s}_{\mathbf{i}} / \mathbf{M s}_{\mathbf{e}}\end{array}$ & $\begin{array}{l}\text { Percentage } \\
\text { Contributio } \\
\mathrm{n}= \\
\left\{\left(\mathrm{ss}_{\mathrm{i}}-\mathrm{df}_{\mathrm{i}}\right.\right. \\
\left.\times \mathrm{Ms}_{\mathrm{e}}\right) \\
/ \mathrm{Tss})^{*} 100\end{array}$ \\
\hline A & 1 & 38.75 & 38.75 & $44.34 *$ & 3.9 \\
\hline B & 1 & 121.5 & 121.55 & $139.23 *$ & 12.55 \\
\hline C & 1 & 129.3 & 129.39 & $148.21 *$ & 13.36 \\
\hline D & 1 & 145.8 & 145.8 & $167 *$ & 15.07 \\
\hline A x B & $\mathbf{1}$ & 58.14 & 58.14 & $66.59 *$ & 5.9 \\
\hline B x C & 1 & 8.26 & 8.26 & $9.46 \mathrm{~ns}$ & ---- \\
\hline A x C & $\mathbf{1}$ & 452.6 & 452.62 & $518.47 *$ & 46.9 \\
\hline ERRO & 8 & 6.98 & 0.873 & & \\
\hline ST & 15 & 961.4 & & & \\
\hline
\end{tabular}

From $\mathrm{F}$ table for $1,8 \mathrm{~F}_{1,8}=5.32$ for $99.95 \%$ confidence $=11.26$ for $99.99 \%$ confidence

Factors with" ${ }^{\text {**” }}$ marks are highly significant.

Table -12: Average response table for surface finish

\begin{tabular}{|l|l|l|}
\hline $\begin{array}{l}\text { Factors/ } \\
\text { Levels } \\
\text { Interaction }\end{array}$ & I & II \\
\hline $\mathrm{A}$ & 19.14 & 16.03 \\
\hline $\mathrm{B}$ & 20.34 & 14.83 \\
\hline $\mathrm{C}$ & 14.74 & 20.43 \\
\hline $\mathrm{D}$ & 14.56 & 20.6 \\
\hline $\mathrm{A} \times \mathrm{B}$ & 19.49 & 15.68 \\
\hline $\mathrm{B} \times \mathrm{C}$ & 16.86 & 18.3 \\
\hline $\mathrm{A} \times \mathrm{C}$ & 12.26 & 22.9 \\
\hline
\end{tabular}


$\mathrm{T}=$ Average $=281.3 / 16=17.58$

Response equation for optimum SF from table-11\& 12 was found to be $A C_{i} D_{i} C_{i} B C_{i i} A B_{i} A_{i i}$

$$
\begin{aligned}
& \mathrm{SF}_{\mathrm{opt}}=\mathrm{T}+\left(\mathrm{AC}_{\mathrm{i}}-\mathrm{T}\right)+\left(\mathrm{D}_{\mathrm{i}}-\mathrm{T}\right)+\left(\mathrm{C}_{\mathrm{i}}-\mathrm{T}\right)+-----+\left(\mathrm{B}_{\mathrm{ii}}-\right. \\
& \mathrm{T})+\left(\mathrm{AB}_{\mathrm{i}}-\mathrm{T}\right)+\left(\mathrm{A}_{\mathrm{ii}}-\mathrm{T}\right)=17.58+(12.26-17.58)+ \\
& \ldots \ldots \ldots+ \\
& (16.03-17.58)=0.70
\end{aligned}
$$

\section{CONCLUSIONS}

MRR: The present sets of experiments give an important insight into the effectiveness of the electrolyte used. The contribution of Sodium Chloride is maximum in that group of electrolytes. The individual factor $\mathrm{Na}_{2} \mathrm{So}_{4}$ and none of the interaction factors produces any contribution as far as MRR is concerned. The response of $\mathrm{NaCl}, \mathrm{NaNo}_{3}$ and $\mathrm{KBr}$ suggest that rather higher levels of these salts will produce better effects.

Surface Finish: The ANOVA table computed for the surface finish effect gives rather interesting insight into the effects of the present set of four electrolytes on the surface finish in ECM of Titanium. While individual contributions have not been as high, the interactions of two factors have a larger contribution on the surface finish. The contribution of $\mathrm{NaCl}$ and $\mathrm{KBr}$ accounts for $46.9 \%$ of the total contribution by all the electrolytes. Among the contribution of individual factors, $\mathrm{KBr}$ has shown a contribution of $13.36 \%, \mathrm{Na}_{2} \mathrm{So}_{4}$ has also shown a high contribution of $15.07 \%$. While most of the effects of the individual factors as well as the interaction of the factors have been shown as highly significant, (at 99\% level of confidence), only the interaction of $\mathrm{NaNO}_{3}$ and $\mathrm{KBr}$ have been insignificant.

Experiments are conducted to find out suitable electrolytes. Following are the conclusions.

1) Out of four different salts experimented; $\mathrm{NaCl}$ is highly significant at $99.99 \%$ confidence. Sodium Nitrate \& Potassium Bromide both are significant at $99.95 \%$ confidence as far as MRR is concerned. Sodium Sulphate and interaction of the salts are insignificant.

2) The contribution of $\mathrm{NaCl}$ is as high as $62.5 \%$, while contribution of Sodium Nitrate and Potassium Bromide are $12.2 \% \& 5.8 \%$ respectively. But Sodium Sulphate and none of the interaction produce any contribution on MRR.

3) All the salts experimented are highly significant at 99.99\% confidence except interaction $\mathrm{NaNO}_{3} \& \mathrm{KBr}$ which is significant at $99.95 \%$.

4) The contribution of interaction sodium chloride \& potassium bromide is as high as $46.9 \%$ on SF. The contribution of $\mathrm{NaCl}, \mathrm{NaNO}_{3}, \mathrm{KBr}, \mathrm{Na}_{2} \mathrm{SO}_{4}$ and $(\mathrm{NaCl} \mathrm{x}$ $\mathrm{NaNO}_{3}$ ) are $3.9 \%, 12.55 \%, 13.36 \%, 15.07 \%$ and $5.9 \%$ respectively. But $\left(\mathrm{NaNO}_{3} \times \mathrm{KBr}\right)$ does not produce any contribution.

5) The combination of factors for optimum MRR is AiiBiiCii.
6) The combination of factors for optimum SF is ACiDiCiBiiABiAi

\section{LIMITATION}

Moroz has suggested many electrolytes for machining VT3-1 as given table 01. But only four of them tested to influence over MRR \& SF. Other electrolytes are not tested due to cost and risk involved in handling them. Better result might have been achieved if all were tested. In other part of experiments, pressure/flow rate of electrolyte has not taken into account because of difficulty in getting control over it.

\section{FUTURE SCOPES}

A data bank can be developed for various Titanium based alloys so that optimized process parameters \& proper electrolytes are readily available for each of them. Computer Interfaced ECM technology may provide better result.

\section{REFERENCES}

[1] S.K.Sorkhel \& B.Bhattacharyya (1992) parametric combination for controlled machining rate and surface quality in ECM pp(421-426) .

[2] Sunil Sharma and P.K.Mishra (1994) electrochemical deburring of drilled cross hole intersection pp(658-659).

[3] A text book on "Chemistry of engineering materials", byRobert.B.Leighou.

[4] J.A.M.C GEOUGH (1974), Principles of Electro Chemical Machining.

[5] A.E.Debarr and D.A.Oliver (1968) ECM.

[6] J.Bannard (1977) Electro Chemical Machining, (review), Journal of Applied ElectroChemistry.

[7] R.Narayan.The role of the electrolyte in Electro Chemical Machining, Chemistry department, IIT, Madras.

[8] Power, R.W.Wilfore J.F. "Some observation on the anodic dissolutlion of Titanium alloys at high current density". General electric research and development centre, Schenectady, New York.

[9] A text book on "Titanium science and technology volume-I", edited by R.I.Jafee and H.M.Burte.

[10] A.G.Degtyavenko, G.I.Fribus (1980) ECM of turbo compressor blades, Russian engineering journal, vol.1, (pp-61).

[11] I.I.Moroz (1978) Recommendations for selecting electrolyte for ECM machines and tooling, vol.1.

[12] Prof. Dr.ir. R.Snoeys (1) et.al. Current trends in non conventional material removal processes, CIRP, (1986), Vol.35.

[13] Raghva Rao (1971), constructions and combinatorial problems in design of experiments John iley and sons inc., New York, pp-286.

[14] Cochran.W.G., and Cox, G.M. "Experimental design" John wiley and Sons, New York.

[15] Taguchi, G. and Yu Inwu (1981), introduction to offline quality control the general Japanese quality control association, pp-82.

[16] A Journal on manufacturing Engineering \& Management (Nov-1971) Volume-67.No.5.pp-22. 
[17]Electro erosion \& electro chemical maching, (In Russion), ministry of machine building \& tool industry, Vol. II.

[18]Dr.S.R.Rajagopalan (1984), final report on the Development of Electrochemical milling machine, National Aeronautical Laboratory, Bangalore.

\section{BIOGRAPHIES}

Dr. Parameswar Dash Passed AMIE (India) in Mechanical Engineering in the year 1989 from the Institute of Engineers (India). Completed master in engineering with Manufacturing Technology as specialization with the first division from the Thaper Institute of Engineering and Technology, Patiala in the year 1999. Was awarded with Ph.D degree in the area robotic assembly sequence generation from the Sambalpur University in the year 2010. Joined as lecturer in IEM, Jeypore (K) in the year 1991. Since then he has been working in different institutions in various capacities besides heading the mechanical dept. for several years. Has published several papers in international journals and conferences. Was awarded gold medal from the Institute of Engineers for the best paper published in the year 2008. His area of interest lies in Flexible Manufacturing, Assembly Sequence generation, Computer aided Manufacturing, Manufacturing Technology etc. Currently, he is serving as professor in the Dept. of Mech. Engineering in Gandhi Engineering College, Bhubaneswar, Odisha, India. 